(RESEARCH ARTICLE)

\title{
A three year review of twin deliveries in a specialist hospital in North-Western
}

\section{Nigeria}

\author{
A. Oyaromade ${ }^{1,}{ }^{*}$, B. A Muhammad ${ }^{2}$ and A. Omigbodun ${ }^{3}$ \\ ${ }^{1}$ Department of Obstetrics and Gynaecology, Ahmad Sani Yariman Bakura Specialist Hospital, Gusau. \\ 2 Department of Obstetrics and Gynaecology, Federal Medical Centre Gusau. \\ ${ }^{3}$ Department of Obstetrics and Gynaecology, University College Hospital Ibadan.
}

International Journal of Frontiers in Life Science Research, 2021, 2021, 01(01), 034-039

Publication history: Received on 15 March 2021; revised on 25 April 2021; accepted on 27 April 2021

Article DOI: https://doi.org/10.53294/ijflsr.2021.1.1.0034

\begin{abstract}
Background: Although the frequency of twin pregnancies varies from one ethnic group to another, there has been a general trend toward an increase recently. Maternal and perinatal mortality are higher in twin than singleton pregnancies. Most studies on twinning had been done in university teaching hospitals where conditions are different from what is seen in secondary-care health institutions where this study was done

Objectives: To determine the incidence, mode of delivery and maternal and perinatal outcomes of twin deliveries at a secondary-level hospital in North-Western Nigeria.

Methodology: This was a descriptive study of 96 twin deliveries over a three-year period between May 2013 and April 2016 at a secondary-level hospital with access to specialist obstetricians and paediatricians.

Result: There were 4,567 deliveries, with 101 twin deliveries, an incidence of $2.2 \%$ or 1 in 45 deliveries. The mean maternal age and parity were 26.4 years and 3.2 respectively. The mean gestational age at delivery was 35.9 weeks, with a mean birth weight of $2.18 \mathrm{~kg}$ and $2.01 \mathrm{~kg}$ for the first and second twins respectively. Male twins constituted $53.2 \%$ of twin births. The common presentations of the twins were cephalic-cephalic (64.6\%), cephalic-breech (16.7\%) and breech-breech (6.3\%). Mode of deliveries were vertex vaginal (77.1\%) and caesarean (14.6\%). Breech presentation of the leading twin was the commonest indication for caesarean section (57.1\%). Anaemia in pregnancy (16.7\%) was the commonest maternal complication, while prematurity was the leading cause of perinatal mortality.
\end{abstract}

Conclusion: Preterm delivery, malpresentation, operative delivery and maternal anaemia in pregnancy were commonly seen in association with twin pregnancy in this cohort of patients.

Keywords: Twin; Pregnancy 2; Maternal mortality; Perinatal mortality; Caesarean

\section{Introduction}

The risk for complications is higher in twin pregnancy during pregnancy, labour and postpartum than that found with singleton pregnancy [1] Twin pregnancy is associated with an increase in both fetal and maternal complications. Some of the maternal complications include anaemia, pregnancy induced hypertension, recurrent miscarriages and preterm labour, while fetal consequences include low birth weight and perinatal mortality. Twin pregnancy is associated with four [4] times the perinatal mortality rate of singleton gestation [2]

\footnotetext{
${ }^{*}$ Corresponding author: A. Oyaromade

Department of Obstetrics and Gynaecology, Ahmad Sani Yariman Bakura Specialist Hospital, Gusau. 
Twin pregnancy is of great obstetric importance in Nigeria because Nigeria has the highest incidence of twinning in the world [3]. Monozygotic twins result from division of a single fertilized ovum while dizygotic twins results from two separate ova fertilize [4].

Monozygotic twins incidence is constant worldwide at 3.9 per 1000 births, while that of higher order pregnancy varies and can be obtained using Helen's rule ( 1 in $80^{\text {n }-1}$ pregnancy)[4] where $n$ is the number of fetuses. There has been tremendous increase in the incidence of twins and higher-order multiple gestation over the past two decades which can be attributed to increased uptake of ovulation - inducing drugs and assisted reproductive technology (ART) [6]. Age, parity, race, genetic and environmental factors have been shown to influence incidence of dizygotic twins. Women who conceive immediately after cessation of long - term oral contraception may also have higher incidence of twinning possibly from high "rebound" gonadotrophin secretion [4, 7]. About ${ }^{2} / 3$ rd of twins may experience intrauterine growth restriction [8] and this may occur in both twins. Hence, early diagnosis and high index of suspicion may help clinicians in obtaining better outcomes.

In view of the apparent increase in the occurrence of multiple gestations worldwide and the attendant higher rates of maternal and fetal complications, and the paucity of research on twinning in Gusau Zamfara State, this study was conducted to determine the frequency, complications and outcome of twin pregnancies in a secondary level hospital with specialist obstetric and paediatric services.

\section{Materials and methods}

This was an analysis of 96 cases of twin pregnancy managed at a specialist hospital in Northwestern Nigeria over a 3 year period spanning from $1^{\text {st }}$ May, 2013 to $30^{\text {th }}$ April, 2016. The clinical case records of all patients who had twin pregnancies during the period were retrieved and information about parity, maternal age, gestational age at delivery, birth weights, mode of delivery, fetal presentation, fetal outcome, as well as other associated complications, were extracted from the records. The data obtained were analysed to determine the frequencies of the characteristics of interest, calculate proportions, means and standard deviation [SD] of these attributes in the patients.

\section{Results}

A total of 4,567 deliveries were conducted at the hospital during the study period and 101 of them were twin deliveries, constituting $2.22 \%$ or 1 in 45 deliveries. However, only 96 case notes were fully available for analysis, giving a retrieval rate of $95.01 \%$.

Table 1 Age and Parity Distribution of Mothers

\begin{tabular}{|l|l|l|}
\hline Age Group (Years) & Frequency & Percentage (\%) (N = 96) \\
\hline $15-19$ & 8 & $(8.3 \%)$ \\
\hline $20-24$ & 24 & $(25.0 \%)$ \\
\hline $25-29$ & 46 & $(47.9 \%)$ \\
\hline $30-34$ & 8 & $(8.3 \%)$ \\
\hline $35-39$ & 9 & $(9.4 \%)$ \\
\hline$\geq 5$ & 1 & $(1.1 \%)$ \\
\hline TOTAL & 96 & $(100 \%)$ Mean 26.4 \\
\hline Parity & \multicolumn{2}{|l}{} \\
\hline $1-2$ & 12 & $(12.5 \%)$ \\
\hline $3-4$ & 68 & $(70.8 \%)$ \\
\hline$\geq 5$ & 16 & $(16.7 \%)$ \\
\hline TOTAL & $\mathbf{9 6}$ & $\mathbf{( 1 0 0 \% )}$ \\
\hline
\end{tabular}


As depicted in Table 1, the maternal age range was from 13 to 45 years while parity ranged from 1 to 14 . The mean age was 26.4 [SD 5.25] years. About $83.3 \%$ were multiparous while $16.7 \%$ were grandmultiparous (parity $\geq 5$ ). The gestation age at deliveries ranged from 30 to 42.0 weeks with a mean of 35.9 weeks. The presentation of twins were cephalic - cephalic in $64.6 \%$, Breech - cephalic in $10.4 \%$, cephalic - breech in $16.7 \%$, breech - breech in $6.3 \%$ while presentation in $2.0 \%$ were not documented as shown in Table 2.

Table 2 Distribution of Twins by Fetal Presentation and Mode of Delivery

\begin{tabular}{|l|l|l|}
\hline Variable & Frequency & Percentage (\%) (N =96) \\
\hline Cephalic - cephalic & 62 & $(64.6 \%)$ \\
\hline Breach - cephalic & 10 & $(10.4 \%)$ \\
\hline Cephalic - Breech & 16 & $(16.7 \%)$ \\
\hline Breech - Breech & 6 & $(6.3 \%)$ \\
\hline Others & 2 & $(2.0 \%)$ \\
\hline TOTAL & 96 & $(100 \%)$ \\
\hline Mode of Delivery & \multicolumn{2}{|l}{} \\
\hline Vaginal & 74 & $(77.1 \%)$ \\
\hline Caesarean Section & 14 & $(14.6 \%)$ \\
\hline Vacuum Delivery & 8 & $(8.3 \%)$ \\
\hline TOTAL & $\mathbf{9 6}$ & $(\mathbf{1 0 0 \% )}$ \\
\hline
\end{tabular}

Table 3 Indications for Caesarean Section

\begin{tabular}{|l|l|l|}
\hline Indication & Frequency & Percentage (\%) (N = 96) \\
\hline Leading twin breech & 8 & $(57.1 \%)$ \\
\hline Previous second twin & 1 & $(7.1 \%)$ \\
\hline Retained second twin & 4 & $(28.6 \%)$ \\
\hline Transverse lie (first twin) & 1 & $(7.2 \%)$ \\
\hline Footing breech (first twin) & 0 & $(-)$ \\
\hline Cord Prolapse & 0 & $(-)$ \\
\hline TOTAL & 96 & $(100 \%)$ \\
\hline
\end{tabular}

Seventy four (77.1\%) of the twins were delivered by spontaneous vaginal delivery, fourteen (14.6\%) by caesarean section and eight (8.3\%) were delivered by vacuum deliveries as shown in Table 2. The commonest indication for the caesarean section as observed in the study was breech presentation in the leading twin (57.1\%) as shown in Table 3.

Maternal complications during pregnancy and delivery occurred in forty $(41.7 \%)$ of twin pregnancy of which anaemia in pregnancy occurred most, sixteen (16.7\%), while hypertensive disorders in pregnancy $8(8.3 \%)$ and ante-partum haemorrhage $2(2.1 \%)$ occurred in that order respectively as shown in Table 4. Fifty two (54.2\%) fetuses were male, while forty four $(45.8 \%$ were females).

The overall mean birth weight of the babies in this study was $2.06 \pm 0.54 \mathrm{~kg}$. The leading twin had an average weight of $2.18 \pm 0.55 \mathrm{~kg}$ while the mean birth weight of the second twins was $2.01 \pm 0.51 \mathrm{~kg}$. 
There were nine perinatal deaths in this study giving a perinatal mortality rate of 105 per 1000 births; 4 (44.4\%) and 3.(33.3\%) occurred in the first and second twin respectively, and (11.1\%) in both twins while (11.1\%) perinatal death was not accounted for.

Table 4 Complications of twin delivery

\begin{tabular}{|l|l|l|}
\hline Complications & Frequency & Percentage (\%) (N =96) \\
\hline Anaemia in Pregnancy & 16 & $(16.7 \%)$ \\
\hline Hypertensive disorders & 8 & $(8.3 \%)$ \\
\hline Post Partum Haemorrhage & 6 & $(6.3 \%)$ \\
\hline Ante Partum Haemorrhage & 2 & $(2.1 \%)$ \\
\hline Preterm Labour & 8 & $(8.3 \%)$ \\
\hline Intra Uterine Fetal Death & 4 & $(4.2 \%)$ \\
\hline No Complication & 52 & $(54.1)$ \\
\hline TOTAL & 96 & $(100 \%)$ \\
\hline
\end{tabular}

\section{Discussion}

The twinning rate seen among the patients delivering at the hospital during the period of the study was 1 in 45 deliveries and more than three-quarters of them were able to achieve vaginal delivery. The main complications that occurred in the patients were anaemia in pregnancy, hypertensive disorders and obstetric haemorrhage.

There has been variations in the incidence of twinning from different regions within and outside Nigeria. The incidence of twin deliveries observed in this study was lower than what had been reported from Ile-Ife, South Western Nigeria [9], in North - Central Nigeria [10]and Ibadan, South Western Nigeria [11]which ranged from 1:19 to 1:30. The rate was however similar to the 1:43 that had been reported from other parts of Northern Nigeria such as Jos, North-Central Nigeria[12], and Kano [13]. Much lower rates, 1 in 67 deliveries, have also been reported from Bauchi, North-Eastern Nigeria [14] and from other parts of the world like the United Kingdom 1 in 53 deliveries[15]and the United States of America 1 in 141 deliveries[16].

It can be observed that the incidence of twinning is higher in the South Western part of Nigeria when compared to other parts of the country and possibly higher in the North - West than the North- East of Nigeria. Consequently, twinning rate may possibly be influenced by the ethnicity, with Yorubas of South - Western Nigeria having the highest twining rate worldwide[17]which might not be unconnected with the highest consumption of yam tubers said to be rich in gonadotropin-like substance[18].

The incidence of twining has been shown to increase with increasing maternal age up to mid-thirties after which it drops sharply due to increasing follicle stimulating hormone level [19]. The incidence is also higher among grand multiparous women, but this was not the case in this study where majority (83.3) were multiparous which was similar to that found in Ile Ife, Ilorin and Kano, [13].However, these studies were hospital-based and may not be a true reflections of the findings in the larger community.

The mean gestation age of delivery was 35.9 weeks which is almost similar to the gestational age of 36 weeks reported in Ile Ife [9] and 36.9 weeks reported in Kano [13]but marginally higher than 35 weeks reported in the rest parts of the worldT[7] This might not be unconnected with the smaller sample size in this study.

Cephalic-cephalic presentation was observed in $64.6 \%$ (highest) in this study which is similar to that observed in other studies, and in conformity with the general observation.

From this study, caesarian section rate was $14.6 \%$ which was lower than $40.0 \%$ observed in Kano, [13] 41.4\% in [12]Jos, $32.6 \%$ in Ilorin[10] but almost similar to caesarean section rate of $18.5 \%$ observed in Bauchi[14]The commonest indication for caesarean section was breech presentation in first twin (57.1\%), similar to that observed in Kano (75.0\%) [13]. 
The mean birth weights in the first and second twins observed were $2.18 \pm 0.55 \mathrm{~kg}$ and $2.01 \pm 0.51 \mathrm{~kg}$ respectively, while the overall means birth was $2.06 \pm 0.54 \mathrm{~kg}$. These were slightly lower than that reported in Jos[12] and Kano [4]which might not be unconnected with better economic status among women in Jos and Kano unlike most women in Gusau, Zamfara State.

Maternal complications occurred in 40 (41.7\%) of cases reviewed in this study. This is much higher than $10 \%$ reported in Kano[13] and 20\% reported in Ile Ife [9]. This might not be unconnected with low economic and educational status as well as high incidence of unsupervised deliveries among women in Gusau.

The commonest complications observed from this study were severe anaemia in pregnancy and hypertensive disorders in pregnancy, which were similar to findings in Kano [13] where hypertensive disorder was the commonest complication but contrasts with findings in Ile Ife where pre-labour rupture of membranes was the commonest complication. The low economic and educational status of majority of the female population in the part of the country where this study was conducted may have contributed to the high frequency of anaemia seen in the pregnant women. Further prospective studies comparing outcome in twin and singleton pregnancies are hereby recommended.

The outcome of twin pregnancies in this secondary-level hospital with specialist obstetric and paediatric cover did not differ significantly from what had been reported from the teaching hospitals in this and other parts of Nigeria. Twin pregnancies continue to be associated with greater risks for the mother and the babies - high maternal complications, high caesarean section rate, high perinatal and maternal mortality and morbidity. Women and their families should be educated on the risks associated with twin gestations and the need to have supervised antenatal, intra -partum and post-partum care. In addition, there is need for provision of better facilities to cater for the neonates since many of them tend to be preterm and low birth weight neonates.

\section{Conclusion}

Twin pregnancies are on the increase worldwide of which Zamfara State in North-western Nigeria is not an exception, however, maternal and perinatal complications from twin-deliveries are seen commonly here in Gusau compared to other parts of the country, hence, female child education, women empowerment, economic promotion as well as provision of adequate health facilities as well as provision of skilled birth attendants in all maternity units should be promoted.

\section{Compliance with ethical standards}

\section{Acknowledgments}

We sincerely acknowledged the management of Ahmad Sani Yariman Bakura Specialist Hospital for the approval and support received in the course of this study

\section{Disclosure of conflict of interest}

There was no conflict of interest.

\section{Statement of ethical approval}

Ethical clearance was obtained from the hospital management and all ethical standards were strictly followed.

\section{Statement of informed consent}

The study was a retrospective descriptive study, hence, there was no need for informed consent.

\section{References}

[1] Olatunji A0; Twinning: A retrospective study at Olabisi Onabajo University Teaching Hospital, Sagamu, Nigeria, Nig. Med Pract.2002; 41:52-5

[2] Bromwich P. The Sex ratio and ways of manipulating it. in; John Study (ed). Progress in Obstetrics and Gynacology, Chirechi II Livingstone, London; Vol. 4 1984: 217- 231. 
[3] Fakeye O, A, Twin birth weight discordance in Nigeria. Int .Journ Gynaecology Obstet. 1986; 24:235 - 238 PMID: 2880763.

[4] Bush MC, Pernoll ML. Multiple Pregnancy. In Dechrney AH, Nathan I, Goodwin TM, Tauffer N, editors. Current Diagnosis and treatment Obstetrics and Gynaecology. 10 $0^{\text {th }}$ ed. New York; McGraw-Hill, International edition, 2007; P. 298 - 307

[5] Fisk NM, Multiple Pregnancies. In: Edmonds DK, editor. Dewhurst's Textbook of Obstetrics \& Gynaecology; $7^{\text {th }}$ ed Oxford: Blackwell Science Ltd. (Publishers) 2008; P. 298 - 307.

[6] Leszcynska-Gorzelak B, Oleszczuk YY, Kiczynska A, Keith LG; Peculiarities of multiple pregnancy; Epidemiology; Ginekol Pol 2000; 71:1327 - 33.

[7] Cunningham FG, Leveno KT, Bloom SI, Hauth JC, Gilstrap LC, Westron KD, editors Multi-fetal gestation. In: Williams Obstetrics 22nd edition. Mc Graw Hill; 2005; P.911 - 48.

[8] Blickstein I, Lancet M. the growth discordant twin. Obstet Gynecol. Surv.: 1988; 43 (9):509 - 515.

[9] Kuti O, Owolabi AT, Fashuba OB. Outcome of twin pregnancies in Nigerian Teaching Hospital. Tropical Obstet. Gynaecol. 2006; 23:132 - 5 .

[10] Isiaka LS, Adesina KT, Saidu MA, IJAIYA MA, Jimoh AAG, Aderibigbe SA: Areview of Twin Gestation in a Tertiary Health Institution in North Central Nigeria, Research Jornal of Medical Sciences 2009; 3(6):198-201.

[11] Mac Gillivray i, Nylander PPS, Corney G. Human Multiple Reproduction. WB saunders co. LTD London 1975.

[12] Mutihir JT, Pam VC Obstetrics Outcome of Twin Pregnancies in Jos Nigeria. Nigeria Journal of clinical Practice 2007; vol. 10:(1): 15-18.

[13] Attah RA, Mohammad Z, Gobir M.A review of Twin Deliveries in Aminu Kano Teaching Hospital, North-West Nigeria, Nigeria Journal of basic and Clinical Sciences 2014; Vol 11 (1):3-7.

[14] Ibrahim SM, Kullima AA, Balkisu I, Umar BAkari MA. Outcome of twin Pregnancies in Federal Medical Centre Azare, Nigeria Bo Med J 2003; 10 (2):1-9.

[15] Waterhouse JA. Twinning in Pedigree. Brit J soc Med 1950; 4:197-215.

[16] Dion My, Marin MJ, Pollack RN. ET al. Twin Gestation; Fetal presentation as a function of Gestational age. Am J Obstet Gynaecol 1993; 168:1500 (PMID: 8498435).

[17] Zhang J, Hamitton B, Martin J, Trumle A. Delayed Interval Delivery and Infant survival; A population-based study Am J Obstet Gynae 2004; 191:470-6.

[18] Obiechina N.J, Okolie VE, Eleje G, Okechukwu Z, Anemeje O. Twin Versus Singleton Pregnancies: the incident Pregnancy Complications and Obstetrics outcomes in Nigerian Tertiary Hospital . Int J Womens Health 2011; 3:227-30.

[19] Adeoye S, Ogbonnaya IU, Umeorah OU, Asiegbu O, Concurrent use of Multiple Antenatal care Providers by Women utilizing free ante-natal care in Ebonyi State University Teaching Hospital, Abakaliki Afr J Reprod Health 2005; 9:101-6. 